\title{
Study on heat dissipation and cooling optimization of the Junction Box of OBSEA Seafloor Observatory
}

\author{
Daniel M. Toma, Antoni Mànuel, Member, IEEE, Marc Nogueras, Joaquin del Rio, Member, IEEE
}

\begin{abstract}
Multidisciplinary underwater observatories represent an exceptional technological resource that can signify a qualitative forward step in marine scientific research as well as operational oceanography and climate change study. A cabled underwater observatory system that can provide broad bandwidth communication and power to oceanographic instruments is developed. The observatory consists of a subsea Junction Box that is fixed at a cable terminal, enabling real-time communication, power conversion, and power distribution of up to eight oceanographic instruments and one connection for a Junction Box. Therefore, the observatory has the capacity to cover a large range of distance-time observations, and to provide new opportunities for research and technological innovation. However, there are some issues to consider when designing the electronic system for the underwater observatory. The main concern is the location of the equipment in a hostile environment with difficult access for inspection and repair. Hence, appropriate heat management of the electronic apparatus has a significant influence on the useful life of this equipment. Specific validation and study of the behavior of the system prior the deployment, and permanent equipment status monitoring is essential to assure fault-free operation over the longest possible period of time. In this article, we present the thermal studies carried out on the Junction Box of the OBSEA (Observatorio Submarino Expandible Cableado) [expandable underwater cabled observatory], and the monitoring procedures established. The underwater observatory has been deployed off the coast of the Balearic Sea and has been operating in real conditions for more than three years without interruption. The results show that this underwater observatory system is adequate for subsea real time and long-term observations.
\end{abstract}

Index Terms - Underwater observatories, power electronics, thermal management, power system reliability, physics-of-failure

\section{INTRODUCTION}

$\mathrm{T}$ HE development and installation of cabled underwater observatories will benefit a large number of areas in marine sciences, for example the study of large scale

Manuscript received January 2014; revised April 2014. The present study was developed in the framework of International and Spanish National research funded actions: ESONET (European Seas Observatory NETwork; FP6-2005-Global-4, ESONET 036851-2), Sineos CTM2010-15459 and ACI20090983 Operative capacity OBSEA Underwater laboratory”.

The authors are with the SARTI Research Group. Electronics Dept. Universitat Politècnica de Catalunya. Rambla Exposició 24, 08800, Vilanova i la Geltrú. Barcelona. Spain. (e-Mails: daniel.mihai.toma@upc.edu, antoni.manuel@upc.edu, marc.nogueras@upc.edu, joaquin.del.rio@upc.edu). circulation variability, biochemical cycles (nutrients balance, carbon flow, etc.), the dynamics of marine ecosystems and internal and external geo-dynamic processes and studies of singular and extreme events (storms, formation of discharge plumes in estuaries, blooming of harmful algae - HABs, earthquakes and tsunamis, etc.). The measurement technologies of underwater observatories enable data collection with sufficient time resolution to register singular events essential in dynamic processes and facilitate in-situ study of specific phenomena.

These technologies are being developed in different countries such as: NEPTUNE [1] in USA-Canada, VENUS [2] in Canada, ARENA in Japan, ALOHA in Hawaii, or European Seas Observatory NETwork (ESONET) promoted by the European Union. This ocean observatory networks will provide continuous supervision of marine phenomena in the geophysics, bio-geochemistry, biology and oceanography fields.

In Spain, a similar cabled underwater observatory "OBservatorio Submarino ExpAndible" (OBSEA) [3] has been developed by the research group responsible for writing this paper and deployed off the coast of the Balearic Sea near Vilanova i la Geltrú (Barcelona). The OBSEA observatory is designed as a site-to-shore system capable of high-voltage power conversion and distribution, real-time data transmission, fault detection and isolation that was developed and successfully deployed in May 2009. The observatory system consists of three main sections: a shore station; an underwater telecommunications armored cable that links the Shore Station and the deployment site; and a first Seafloor Node, or Junction Box, capable of being expanded with more underwater nodes and surface buoys. The underwater telecommunications cable is an electrical-optical cable providing power and real-time communication to the instruments and equipment of the observatory. The shore station is located in the facilities of the Technical University of Catalonia and the Seafloor Node is located at $4 \mathrm{~km}$ off the coast of Vilanova i la Geltrú, at a depth of 20 meters as depicted in Figure 1. 


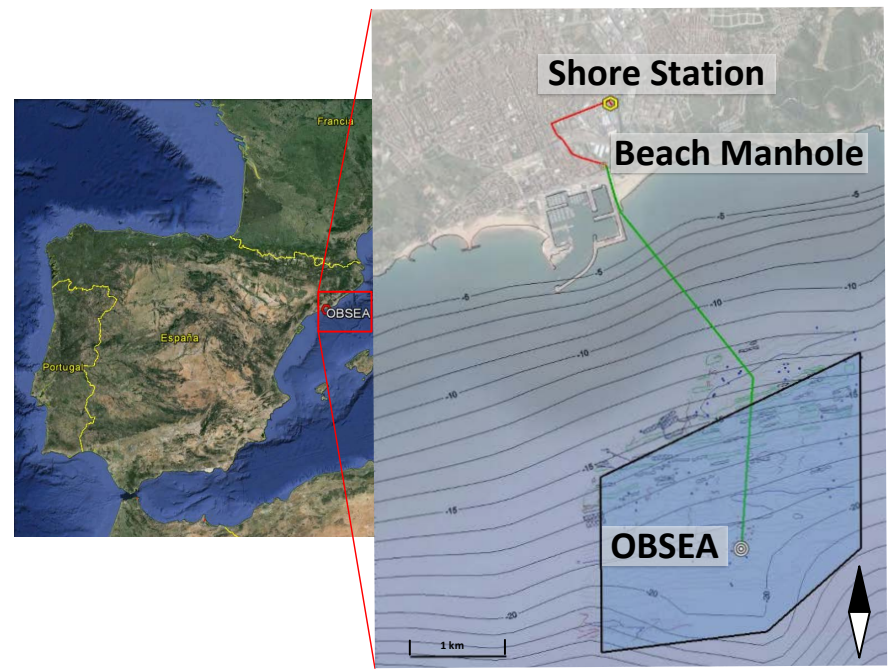

Figure 1. Location of the OBSEA observatory

The Seafloor Node is a stainless steel pressure cylinder rated to $300 \mathrm{~m}$, containing off-the-shelf and custom electronics. The Junction Box, which is connected to oceanographic instruments, contains the power supply, communications and control systems of the node as can be seen in the diagram in Figure 2. The design and construction of these systems was carried out considering redundancy mechanisms for single failure resist. In addition, stress tests and continuous verification procedures have being carried out during assembly. However, of all these systems, it is the power supply system that is subject to the most rapid fatigue, due to the high voltages and temperatures that its electronic components have to endure.

Therefore a reliability study prior to the installation of the observatory is essential. Moreover, because it is difficult to establish an operative intervention offshore without the permanent availability of well-equipped vessels and an elevated budget, rapid repair of a fault in the observatory system poses immense difficulties, and this may result in a lengthy interruption of the service from anything between several weeks and several months.

In this paper, an overview of the thermal management of OBSEA Junction Box is presented. Section 2 focuses on the design philosophy of the Junction Box including pressure cylinder mechanical construction, Ethernet communication, high-voltage power transmission, power conversion, and heat dissipation solution. A prototype, built and fully tested in a laboratory environment focused on the reliability and thermal analysis, is presented in Section 3. The actual deployment of the OBSEA observatory and the results are discussed in Section 4. Finally, the conclusions drawn are presented in Section 5.

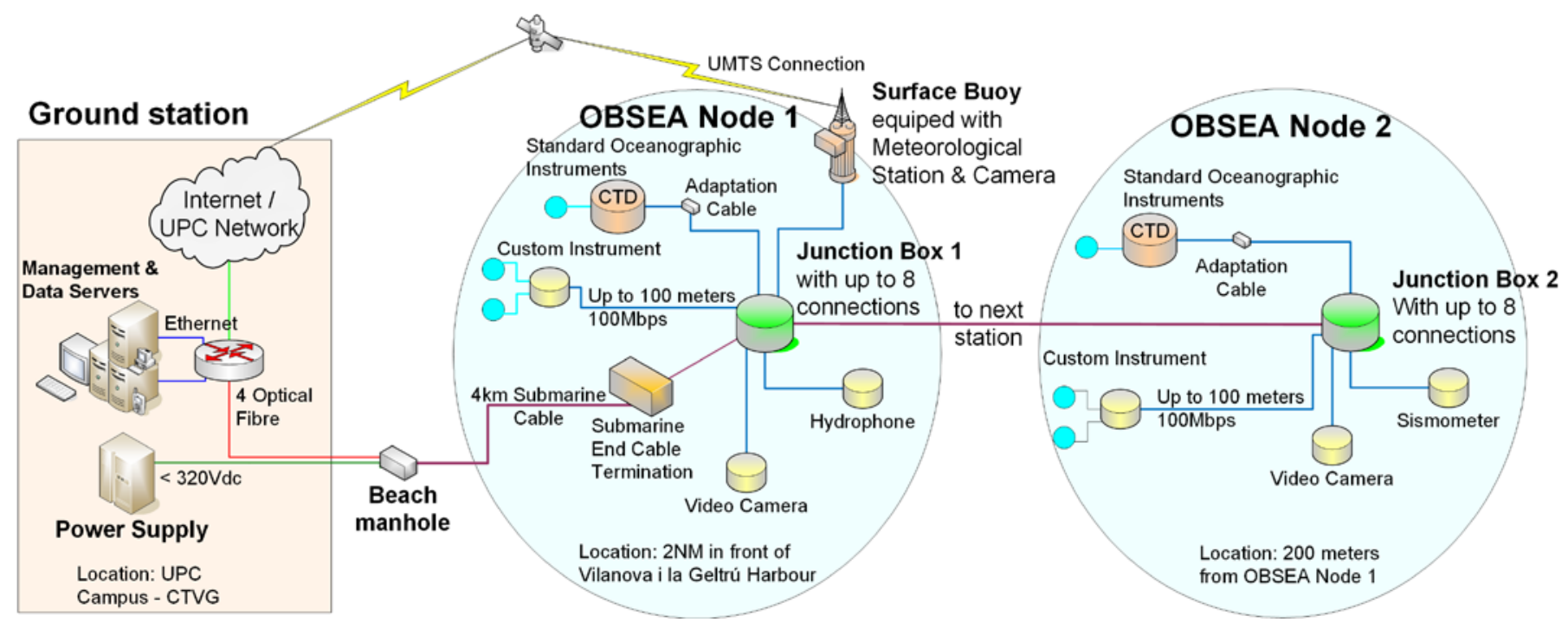

Figure 2. Diagram of the OBSEA observatory. Detail of the observatory electronics.

\section{JUNCTION BOX DESCRIPTION}

The design of the OBSEA underwater observatory follows the route initiated by other experiments, such as the ALOHA Cabled Observatory of the University of Hawai'i at Manoa (http://aco-ssds.soest.hawaii.edu/) [4] and the MARS of the Monterrey Bay Aquarium Research Institute (http://www.mbari.org/mars/), among others.
The mechanical design of the main cylinder is shown in Figure 3. The Junction Box is a stainless steel cylindrical pressure vessel approximately $400 \mathrm{~mm}$ in diameter, $1000 \mathrm{~mm}$ in length and with a wall thickness of $5 \mathrm{~mm}$. The pressure vessel is designed to withstand depths of $300 \mathrm{~m}$. All the electronic devices included in the Junction Box, both the commercial components, such as the power supplies and Ethernet switches, and the custom systems are assembled in a single standard 19 inch $6 \mathrm{U}$ (six rack units) sub-rack. 
This sub-rack has also been equipped with intermediate connectors, which improves maintenance access, easy assembly and machining.

\section{OBSEA 1 junction box}

Thickness: $5 \mathrm{~mm}$ Tube, $35 \mathrm{~mm}$ covers. Made of SS $316 \mathrm{~L}$

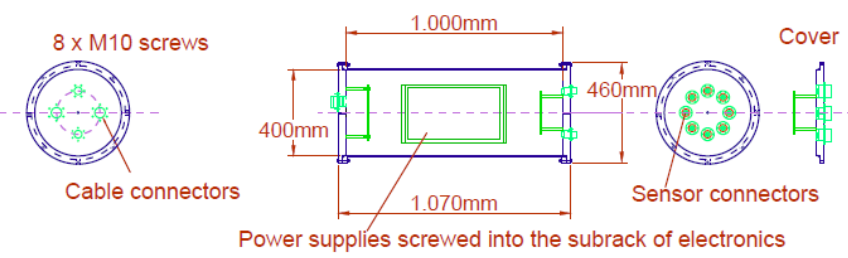

OBSEA 2 junction box

Thickness: $5 \mathrm{~mm}$ Tube, $20 \mathrm{~mm}$ covers. Made of SS $316 \mathrm{~L}$

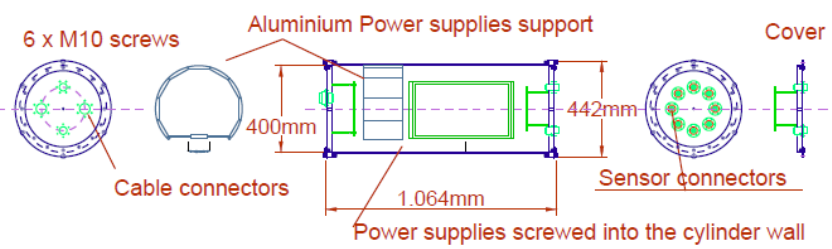

Figure 3. The design of the main cylinder hosting the Junction Box. Sizes and distances are shown in millimeters

Communications from the Shore Station to the Junction Box is 1000BaseLX fiber optic Ethernet (either single or redundant links) allow 10/100Mbps Ethernet connection. Offthe-shelf industrial Ethernet switches route data to and from the Shore Station control computer and the eight instrument interfaces as required.

At present, the observatory system is powered from the Shore Station with a $3.6 \mathrm{~kW}$ power supply of 320VDC. For future development of the observatory system, the power supply can be set up to 1000VDC delivering more power and allowing nodes deployment at a longer distance from the coast. The Junction Box has up to eight wet-mateable ports for oceanographic instruments; all ports can individually supply 12 or $24 \mathrm{VDC}$ at $75 \mathrm{~W}$.

The Junction Box power supply system was designed with off-the-shelf switched DC/DC converters, as these are proven designs with millions of hours of accumulated operation, something that would have been impossible to achieve with our development. The DC/DC converters used are MeanWell converters that allow input voltages in DC from 124 to $370 \mathrm{Vdc}$ [5]. Therefore, following the concept of the $\mathrm{H} 2 \mathrm{O}$ observatory (Hawaii 2 Observatory) of the S.O.E.S.T. University of Hawaii [6], the power conversion system can be developed with a stack of converters connected in series that would permit operation with supply voltages of up to 1000VDC.

In an effort to maximize the time between the faults that could render the system completely inoperative, the Junction Box of the OBSEA has been developed using multiple commercial power supplies that operate in redundancy. The power supply system of the Junction Box has two 370 to 48VDC DC/DC converters of 150W each, connected through parallelization diodes with a lithium-ion battery of 45VDC and 5.4Ah. With this system the underwater node can be supplied with up to $150 \mathrm{~W}$ with $1+1$ redundancy and capable to operate for 4 hours with battery power, if the land power supply system fails. The second stage of power sources is made up of three 48 to $12 \mathrm{Vdc}$ DC/DC converters of $50 \mathrm{~W}$ each, providing a redundancy of $2+1$ at a maximum load of 100W.

The node system is controlled by a ColdFire microcontroller board (www.freescale.com) to which we have added an acquisition system of 32 analogue inputs and 32 digital outputs, that allow us to monitor all the critical parameters of the system, and to control each individual device. The control system communicates with the management server in the Shore Station through SNMP (Simple Network Management Protocol). The management server runs two main software, one LabView application (www.ni.com/labview) for manual operation of the Junction Box, and Zabbix (www.zabbix.com) network management software illustrated in Figure 4, to monitor and store the state of the whole system. A powerful features of this management software is the possibility to merge data from different sources in a single graph, which proves very useful when monitoring multiple parameters of the Junction Box. Also, this management software allows us to configure alarms based on the Junction Box parameters such as rise in temperature, power supplies' current, etc.

In order to test the temperature stress of the Junction Box, the whole electronic system was installed, assembled in its final location and started up inside the cylinder, which in turn was placed in a hyperbaric chamber, to simulate as faithfully as possible the real working conditions. The node was subjected to different loads up to the design limit, to verify the capacity of the thermal management.

\section{RELIABILITY. TEMPERATURE DISSIPATION IN ELECTRONIC SYSTEMS.}

The reliability of an electronic system can be described as the probability of finding a component operating after a time period, and can be defined as an exponential function:

$$
R(t)=e^{-\lambda t}
$$

Where $\mathrm{R}(\mathrm{t})$ is the reliability function, or the probability of a device not failing prior to some time $t$, and $\lambda$ is the failure rate. Therefore, the mean value of $R(t)$ occurs at $t$ equal to $1 / \lambda$, which is the mean time elapsed until a fail occurs and can be approximated by the Mean Time Between Failures (MTBF) [7]. The MTBF is typically part of a model that assumes that the system that has failed will be repaired immediately (the time passed is zero) as part of a renewal process. The MTBF is simply the reciprocal of failure rate $l$.

$$
\mathrm{MTBF}=1 / \lambda
$$




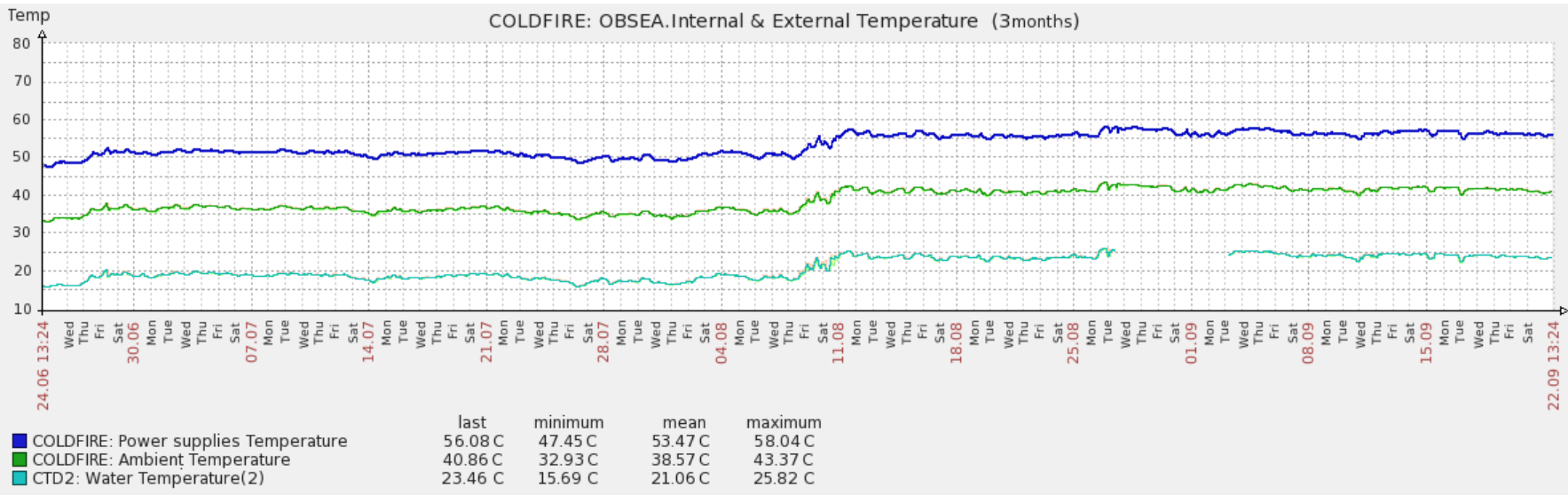

Figure 4 Data screen acquired in Zabbix management software. In graph are depicted 3 months, starting with May 24, 2013, of water temperature, temperature inside cylinder and power supply temperature of OBSEA in the deployment place (20m depth).

As OBSEA is a prototype and is continually being improved and renewed, it is not possible to obtain a reliable value for the MTBF of the system as a whole. However, for the off-the-shelf components such as the power supply, the MTBF value at 25 degrees is given by the manufacturer. For example, the manufacturer of the power supplies provides an MTBF of 183,300 hours at $25^{\circ} \mathrm{C}$, but this drops to 45,000 hours if the temperature increases up to $45^{\circ} \mathrm{C}$. Therefore, it is important to carry out an analysis of the thermal dissipation behavior with the aim of improving the failure rate (MTBF) of the OBSEA Junction Box power supply system.

It is well-known that the life span of electronic systems is very closely related to the temperature at which operation is maintained. So, in an environment where repair is very costly and complicated, all possible methods to reduce the working temperature to the maximum should be considered, along with safety mechanisms to avoid the system having to work in undesirable conditions. [8]. The ability of a particular semiconductor package to dissipate heat to its environment is expressed in terms of thermal resistance (Rth(j-a)) [9, 10]. This single entity describes the heat path impedance from the active surface of the semiconductor device (junction) to the ambient operating environment. Rth(j-a) can be expressed by its constituents as follows:

$$
\operatorname{Rth}(j-a)=\operatorname{Rth}(j-c)+\operatorname{Rth}(c-a)
$$

Where Rth(j-c) is the impedance from junction to the casing (the outer surface of package) and Rth(c-a) is the impedance from casing to ambient. It is sometimes useful to use only the Rth(c-a) to describe high performance packages where casing temperatures are important and externally attached heat radiators may need to be attached. In these cases the overall Rth(j-a) will also include the contribution of the heat radiator.

The main ways to dissipate the heat generated by the electronic components inside Junction Box is through convection and conduction. Moreover, the conventional heat dissipation systems that influence Thermal Resistance include [11]:
* Natural convection and radiation (transfer of heat energy to a fluid, primarily air).

* Forced Convection Cooling (transfer of heat energy to a moving fluid).

* Conduction cooling (transfer of heat through a solid medium).

* Other cooling systems (Fluid phase change, Thermo-ionic or Liquid).

Various studies have been carried out on thermal management, such as [12], which provides an analytical model for thermal profile in 2D chip to determine the peak temperatures of sources on conducting substrates, and for determining the thermal "zone of influence" or "footprint" associated with a component on a board. Other more recent studies focus on the understanding of thermal behavior and heat transfer in Embedded Power Modules. These studies seek to understand the effect of the material properties and geometrical sizing of specific structure on the thermal performance and the stress distribution of planar multi-layer structures. Moreover, new cooling strategies such as liquid cooling, two-phase cooling or spray cooling that can be integrated structurally into the Embedded Power modules are recommended to be used [13]. Maclachlan propose in [14], the use of high thermal conductivity carbon fibers with significantly thermal conductivity in the longitudinal (650 $1100 \mathrm{~W} / \mathrm{mK})$ and radial directions (15 - $50 \mathrm{~W} / \mathrm{mK})$. These fibers can function like thermal 'pipes' to directionally transport heat from one location to another. Other techniques proposed in [15] are the use of foams such as carbon/graphite, silicon carbide and boron carbide as thermal insulators or thermal conductors that also have good mechanical properties. Thermal management in electronics becomes more challenging as the size of electronics decreases, yet the heat generated from electronics still increases. In [16] are experimentally shown techniques that enhance the cooling efficiency of conventional cooling schemes such as heat pipes, using electrowetting on dielectric (EWOD) digital microfluidic to force the cooling liquid medium to move to hot 
spot areas. Other techniques are the use of heat sinks with embedded L-shaped heat pipes and plate fins. These types of heat sinks are particularly well suited for cooling electronic components such as microprocessors using forced convection [17].

However, because the Junction Box is part of an underwater observatory and should be built in such a way that it has a minimum impact on the environment, cooling systems that generate noise and vibrations that could affect marine life or geophysical measurements have to be rejected. Moreover, we should consider the complexity of developing a sophisticated dissipation system with moving parts that can have a greater likelihood of failure. In addition, some of the cooling techniques described above are using experimental materials that are very difficult to find and require special manipulation methods. Also, it is necessary to avoid the use of cooling liquid in the Junction Box because of the maintenance problems that such a method generates.

Giving the existing thermal management methods and the requirements of underwater observatories, the cooling technique proposed for the Junction Box is to mount the power supplies directly to the inside wall of the cylinder or on a chassis with high thermal conductivity. Among the advantages of the OBSEA cooling system design is that the casing of the Junction Box is a sealed stainless steel cylinder that will be submerged in water of a relatively low temperature, from $10{ }^{\circ} \mathrm{C}$ up to $25^{\circ} \mathrm{C}$. Considering this situation, the best cooling system is the one that transfers the greatest amount of excess heat generated by the power supplies to the walls of the cylinder. As described above, the most appropriate solution is to attach the power supplies directly to the inside wall of the cylinder. Although this method was not implemented in the first Node, the Junction Box 1 (JB1) because of its complexity, the power supplies components must rule out those resulting in a mechanism that is complicated to assemble and dismantle; it was used for the construction of the second Node, the Junction Box 2 (JB2), for better heat dissipation as shown in Figure 5.

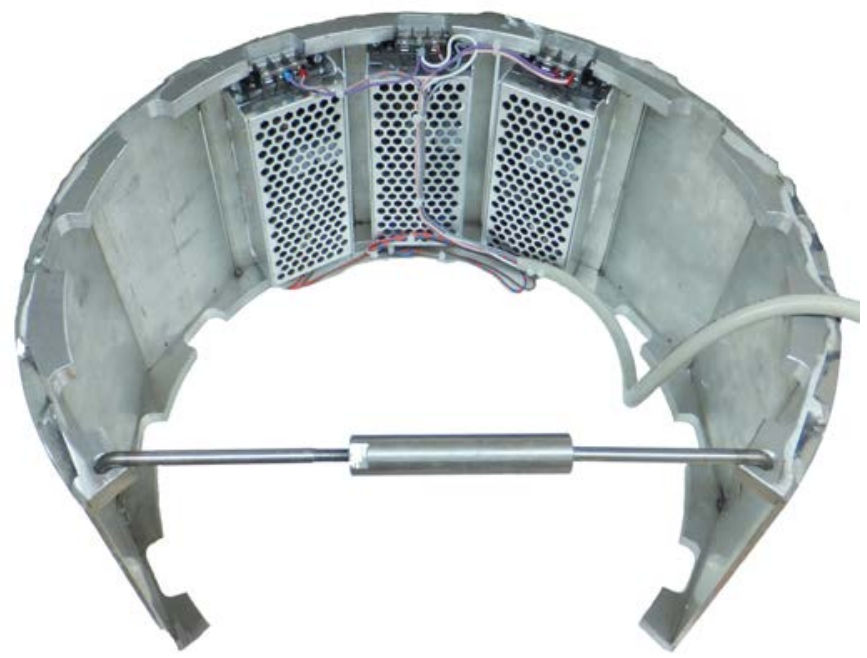

Figure 5 Attachment support of the power supplies inside the wall of the JB2 cylinder
The method used for the first Junction Box was an assembly of heat radiating elements that will transmit the greatest possible quantity of energy into the air inside the cylinder. These radiators have been placed on the existing radiating surfaces on the power supplies to reduce the thermal resistance of these power supplies. Another alternative considered was to develop metallic elements that would conduct heat directly between the power supplies and the cylinder. This option has not been rejected, but also due to the technical difficulty involved in the creation of these custom-made elements we have been obliged to defer this for other versions of the Junction Box.

Once the design of the sub-rack that contains all the Junction Box components is defined, only one parameter, the air pressure found inside the cylinder has to be analyzed. The air pressure parameter can have a great impact on the thermal resistance Rth(j-a). Given that cooling is mainly created by convection, which means that air absorbs the heat of the hot elements and transfers it to the cold ones, the greater the number of air molecules the better the thermal transfer will be. To test this assumption and quantify the relationship between thermal evacuation and air pressure, we have carried out a series of tests with the Junction Box. These tests have been made modifying the pressure of the air inside the cylinder that contains all the electronics, with the power supplies providing maximum power to an external load and with the cylinder submerged in the hyperbaric chamber with water under pressure.

These tests have been very useful, as there is a need to reach a balance between thermal resistance and air pressure in the cylinder. The higher the pressure of the air the lesser the thermal resistance, but for safety reasons this cannot be increased indefinitely. The cylinder is designed to withstand an external pressure of up to $30 \mathrm{Bar}$, but moreover it is designed so that external pressure helps to assure sealing, whereby the internal air pressure should be lower than the existing pressure at the working depth of the observatory. Another aspect to consider is that it is advisable to have a low humidity level to avoid the creation of condensation because of the temperature changes that occur in the installation of the observatory, as the cylinder goes from warm air to cold water. Therefore, to lower internal humidity it is necessary to extract air, which means lowering the pressure. Yet, a low pressure has a negative effect on the cooling system, thus a tradeoff between the need for low pressure to reduce condensation and the need to maintain sufficient pressure for good thermal management is needed. Hence this study on the thermal behavior in the OBSEA Junction Box is done to find the appropriate air pressure inside cylinder in order to fulfill the requirements explained above.

\section{THE PROPOSED MEASUREMENT SYSTEM FOR OBSEA JUNCTION BOX}

\section{A. Measurements system and experimental results}

To carry out the temperature measurements, the complete cylinders of the Junction Boxes were assembled, as used in the 
observatory, and were placed in a hyperbaric chamber illustrated in Figure 6. To measure the internal conditions of the cylinders two sensors measuring temperature and humidity are used. One sensor (WM33-4-XX-H-T1 from Michell Instruments) is placed on the baseplate of the main power supply, and other sensor (SHT11 from Sensirion) is used to provide the ambient temperature of the air in the cylinders. Moreover, voltage and current measurements are taken of all the critical parameters of the system. All the sensors are controlled by the ColdFire microcontroller of the Junction Box, which periodically sends the data to the Zabbix management server using the SNMP protocol. To understand the external working conditions of the cylinder a SeaBird SBE37SMP CTD instrument is installed outside the cylinders to measure the water temperature inside the hyperbaric chamber, as well as the pressure and salinity.

To test the maximum load condition of the Junction Boxes, an external load of approximately $200 \mathrm{~W}$ is used. The tests were carried out over several days and at different pressures, from 0.5Bar up to 2.5 Bar. Figure 7 and Figure 8 show the water temperature, temperature inside the cylinder and power supply temperature graphs resulting from thermal behavior tests on JB1 and JB2.

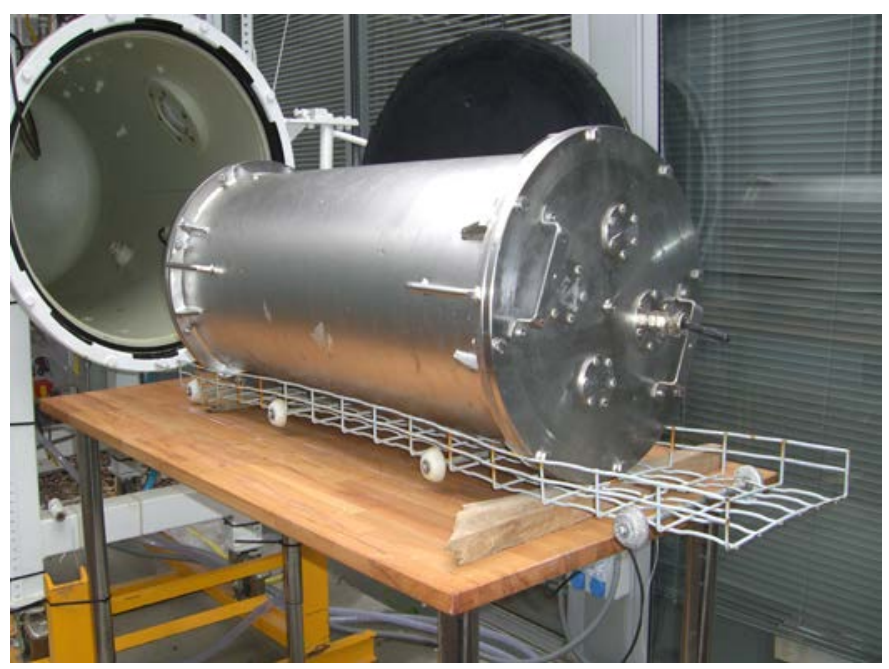

Figure 6 OBSEA Junction Boxes under test in hyperbaric chamber

The graph in Figure 7 shows that the temperature of the JB1 power supply is maintained very high, especially if the pressure inside the cylinder is below one atmosphere, and has a clear dependence with the ambient temperature inside the cylinder. The graph in Figure 8 shows that the temperature of the JB2 power supply is maintained for all tested pressures at low values due to conduction cooling through the cylinder wall in the water and mostly depends on the temperature of water.

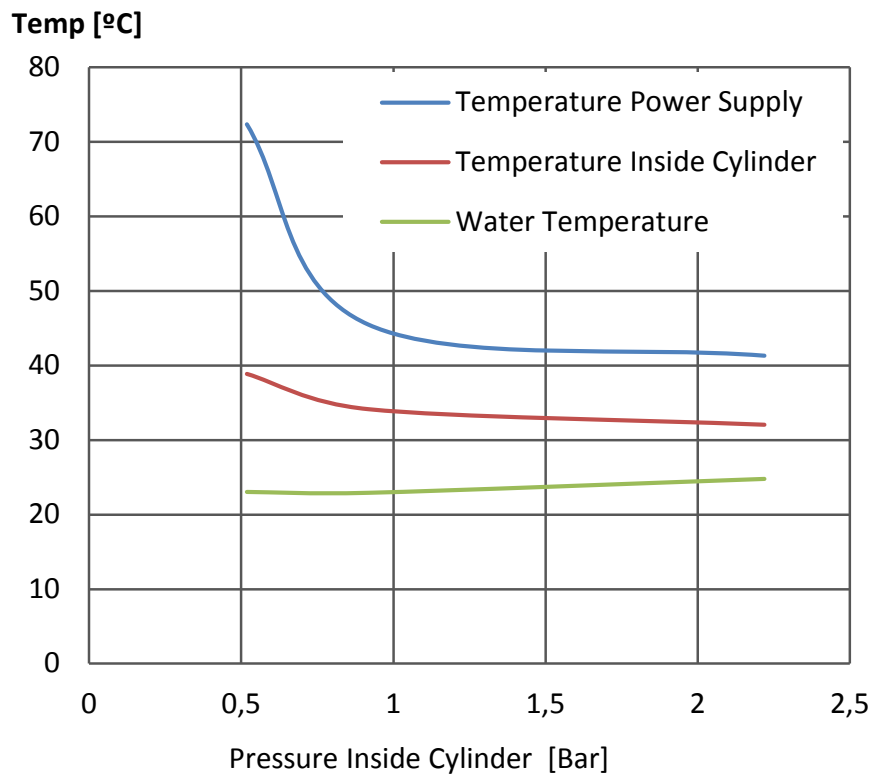

Figure 7 Illustration of the OBSEA JB1 water temperature, temperature inside cylinder and power supply temperature at different pressures, from 0.5Bar up to $2.5 \mathrm{Bar}$

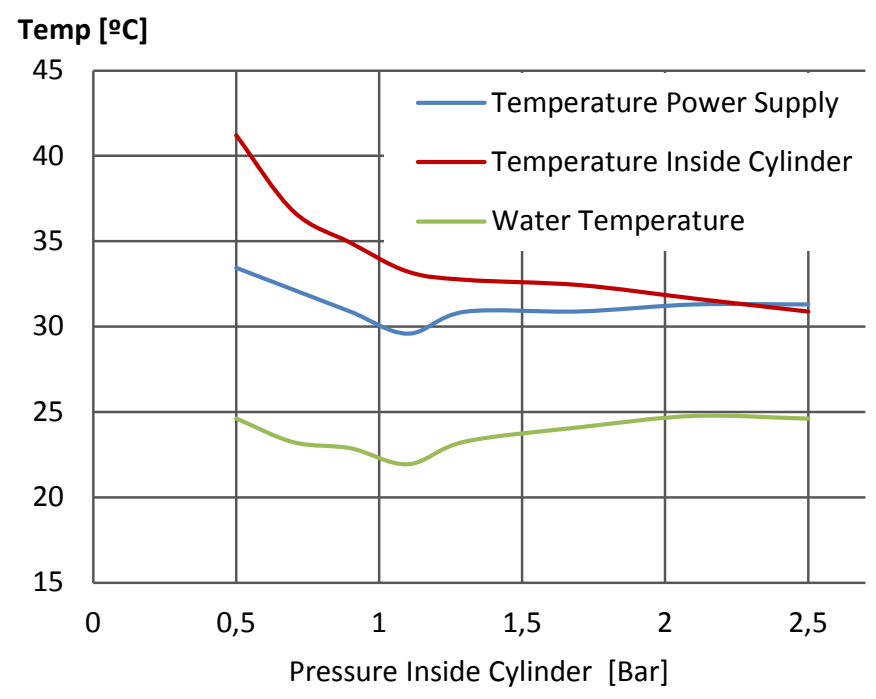

Figure 8 Illustration of the OBSEA JB2 water temperature, temperature inside cylinder and power supply temperature at different pressures, from 0.5Bar up to $2.5 \mathrm{Bar}$

From the temperature measurements taken, knowing that the power provided by the power supplies is of approximately $200 \mathrm{~W}$, and that they operate at an efficiency of $75 \%$, the thermal resistance can be calculated according to the formula:

$$
R_{t h}=T_{r} / P_{d}
$$

Where $\mathrm{Tr}$ is the temperature rise and Pd is the dissipated power. The dissipated power can be calculated with the difference between the input power and the output power of the Junction Boxes. Giving the efficiency of the power supply, of $75 \%$, this can be calculated using the following equation:

$$
P_{d}=P_{\text {in }}-P_{\text {out }}=\left(P_{\text {out }} / 0,75\right)-P_{\text {out }}
$$


In (4) the output power is $185 \mathrm{~W}$, resulting in a dissipated power of approximately $62 \mathrm{~W}$.

In the JB1, the thermal dissipation of the Power Supplies is done mainly through natural convection and radiation in ambient air inside the cylinder rising its temperature, but the temperature of the water will remain constant given the immense volume of the seawater. Therefore, for the JB1 we calculated the thermal resistance between the base plate of the power supplies and the internal ambient of the cylinder Rth (PS-A), the resistance between the ambient and the water Rth (A-W), and the sum of the two Rth (PS-W). In the JB2, the thermal dissipation of the Power Supplies is done mainly through conduction cooling through the cylinder wall in the water. Hence, for the JB2 we calculated the thermal resistance between the base plate of the power supplies and the water Rth (PS-W) and the resistance between the ambient and the water Rth (A-W).

The graph in Figure 9 illustrates this. We can clearly observe from this graph that there is a direct relationship between the thermal resistance and the air pressure inside the cylinder. Moreover, the graph shows the clear difference of the thermal resistance between power supply system and water (Rth (PS-W)) of the two Junction Boxes. The thermal resistance, Rth (PS-W) of JB2 is three times lower than Rth (PS-W) of JB1, and therefore it dissipates the heat generated by the power supplies to the water much better. Therefore, the ambient temperature inside JB2 cylinder is maintained lower than ambient temperature inside JB1 cylinder, resulting in better operating conditions for the entire electronics of the Junction Box.

\section{Rth [을}

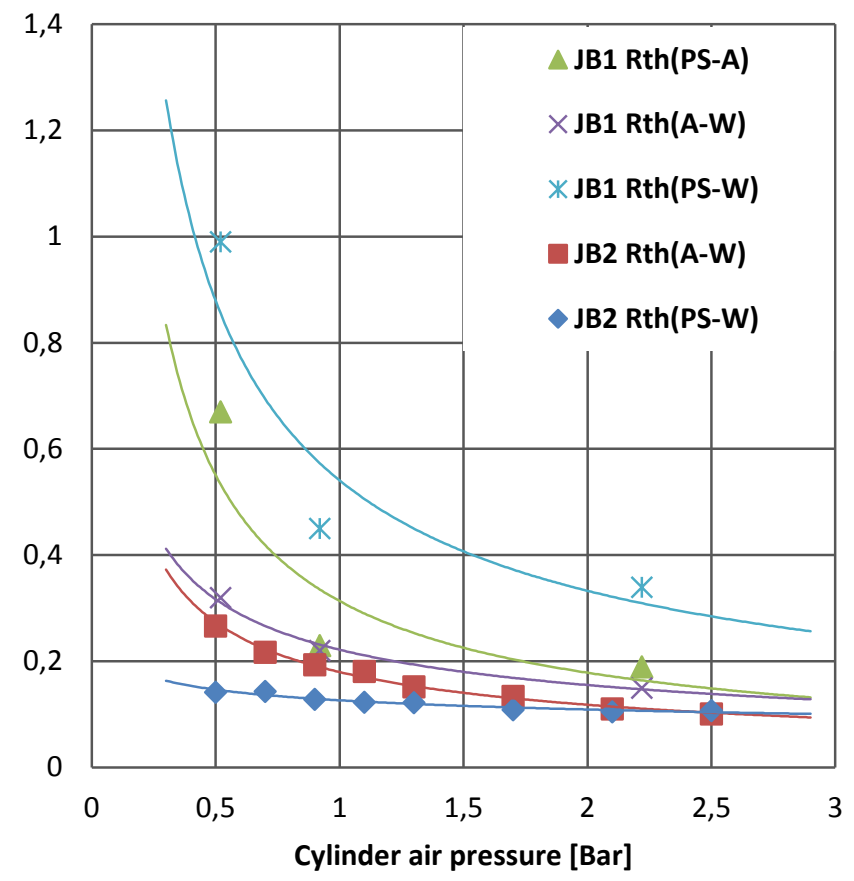

Figure 9 Thermal resistance of power supply-to-ambient Rth(PS-A), ambientto-water Rth(A-W) and power supply-to-water Rth(PS-W) of the two Junction Boxes (JB1 and JB2) at different pressures, from 0.5Bar up to 2.5Bar

\section{B. MTBF and lifetime prediction results}

Giving the results on the thermal behavior of JB1 and JB2, we went on to calculate the MTBF value for the power supply system at a pressure in the cylinder which was slightly below one atmosphere (0.9). It is known that the life span of electronic systems is very closely related to the temperature at which operation is maintained. Therefore we first calculated the failure rate for the condition at which operation of power supply is maintained. The failure rates are normally given under normalized or typical conditions (load, voltage and temperature), and are referred to as basic failure rate $\lambda_{\mathrm{b}}$. To find the actual failure rate for a given condition, $\lambda_{b}$ should be multiplied by the acceleration factor (c).

$$
\lambda_{p}=\lambda_{b} \pi_{T} \pi_{Q} \pi_{E} \text { Failures } / 10^{6} \text { hours }
$$

Where:

$\Pi_{\mathrm{T}}=$ Temperature stress factor

$\Pi_{\mathrm{Q}}=$ Quality factor (mil-spec qualification level vs. non mil)

$\Pi_{\mathrm{E}}=$ Environment factor (environment in which the relay is being used)

The values and the calculations of the different parameters in the equation (6) can be found in the MIL-HDBK-217 [18], a standard tool for use in performing reliability predictions on electronic equipment. Therefore, the temperature stress factor $\left(\Pi_{\mathrm{T}}\right)$ at which the components are working depends on the working temperature in the following way: $\Pi_{\mathrm{T}}=0.8$ for $15^{\circ} \mathrm{C}$, 1 for $30^{\circ} \mathrm{C}, 1.2$ for $45^{\circ} \mathrm{C}, 1.5$ for $55^{\circ} \mathrm{C}, 2$ for $70^{\circ} \mathrm{C}$. The quality factor of the MeanWell converters is $\Pi_{\mathrm{Q}}=1.5$ (Mil Spec) and the Environment factor is $\Pi_{\mathrm{E}}=2$ (Ground fixed). The basic failure rate $\lambda_{b}$ of the MeanWell converters used in the OBSEA Junction Boxes, can be found power supply specifications provided by the manufacturer, and is $5.45 / 10^{6}$ hours. Hence, the final failure rate of the power supply of JB1 operating at approximately $50^{\circ} \mathrm{C}$ and JB2 operating at approximately $30^{\circ} \mathrm{C}$ is $14.1 / 10^{6}$ hours and $11.7 / 10^{6}$ hours respectively. The MTBFs of power supplies are 70960 hours of JB1 and 85477 hours of JB2.

\section{Methods to Improve Reliability}

1) Optimized design of power supply heat dissipation.

Thermal behavior of the power device can be improved by conduction cooling through the Junction Box cylinder wall. The results shown in Figure 9 imply that the selection of the conduction cooling for OBSEA Junction Box power supplies has significant impact on the thermal resistance of power supply-to-water Rth(PS-W). The loss and thermal in the most stressed devices can thereby be reduced, and therefore the lifetime can be increased.

2) On-line condition monitoring.

Condition monitoring is an effective way to enhance reliability when the power converters are in operation [19]. It provides the real-time operating characteristics and health conditions of the systems by monitoring specific parameters of power electronic components (e.g. power supply temperature) and Junction Box ambient (e.g. temperature, humidity and pressure). Therefore, proactive maintenance work, based on 
the predicted lifespan results, could be planned to avoid failures that may occur.

3) Selection of proper devices.

Comprehensive analysis on the device selection based on both cost and performance is needed to avoid either over engineering design or fail to meet the specifications [20]. The selection of power supply modules has significant impact on the overall lifespan of the OBSEA Junction Box.

\section{CONCLUSIONS}

The implementation of marine observatory networks on a regional scale has been considered within the ESFRI (European Strategy Forum for Research Infrastructures) Roadmap, as a European infrastructure of enormous strategic interest. The scientific community, as well as the social counterpart (e.g. the governmental funding agencies) is expressing an increasing interest in extensively monitoring the marine environment to solve current and future problems related to sustainable exploitation and management of marine resources [21]. In particular, the public counterpart is asking the scientific community to create a feasible technology for the continuous and automated measurement of habitat and biological data through space and time [22].

An observatory with the characteristics of OBSEA for operating in shallow waters will provide researchers, at a European level, with the opportunity to test scientific equipment (new sensors) and allow them to carry out these tests in an easily accessible area connected on-line to the network. Within this framework, we hope OBSEA will fulfil the needs of long-term studies based on powerful meta- and bio-data time series for the conservation and renewable management of marine coastal resources.

Moreover, it has become necessary to carry out exhaustive reliability tests, and among these the experimental studies on working temperature management of the electronics located in the Junction Box have been presented in this paper for the following reasons:

* To ensure quality and reliability in this instrumentation system.

* To develop sustainable concepts for best practice and training aimed at defining quality assurance procedures.

* And to allow uninterrupted operation of the installation and therefore permit collection of extensive series of recorded data.

All the working tests were carried out in a water temperature close to the maximum temperature that is reached in the zone of the observatory, so it can be considered that the results are valid for real operation. With these tests we have seen that when pressure in the cylinder is slightly below one atmosphere, the temperature of the power supply of JB1 can be kept almost all the time below the temperature at which derating begins $\left(50^{\circ} \mathrm{C}\right)$ and the temperature of the power supply of JB2 can be kept cool all the time at around $30^{\circ} \mathrm{C}$. Also, we have observed that lower internal air pressures mean that the temperature can increase dangerously especially in the JB1 cylinder. With a pressure of $0.9 \mathrm{Bar}$, we have an advantageous situation in that the pressure differential between the exterior and the interior of the cylinder is always positive, which means that there is less risk that an O-ring might be displaced during the deployment of the observatory, which could lead to water leaking into the cylinder. Given that a series of underwater nodes are being built with the same size and mechanical performance characteristics, these tests have also been useful to improve forthcoming designs of new versions of the Junction Boxes. These new designs should have more on-board power for the same cylinder volume, with the consequent need to evacuate excess thermal energy. This is why the techniques applied in this study are specially useful

\section{REFERENCES}

[1]. NEPTUNE Real-time, Long-term Ocean and Earth Studies at the Scale of Tectonic Plate. National Oceanographic Partnership Program, University of Washington, Seattle, 2000. www.neptune.washington.edu.

[2]. T. Austin, et. al., "The Martha's Vineyard coastal observatory: a long-term facility for monitoring air-sea processes," Proc. Oceans 2000, Providence, pp. 19371941, 2000.

[3]. Mànuel, A.; Nogueras, M.; Del Rio, J. OBSEA an Expandable Seafloor Observatory Sea Technology 2010, 51(7), ISSN: 0093-3651),

[4]. R. Butler et. al., "Hawaii-2 observatory pioneers opportunities for remote instrumentation in ocean studies,” Eos, Transactions, American Geophysical Union, Vol. 81, April 11, 2000, pp. 162-163.

[5]. 2 - 155W Single Output with Battery Charger UPS Function specification sheet AD-155-SPEC 2005-09-13

[6]. Harris, D.W et al, Powering Cabled Ocean Bottom Observatories. IEEE Journal of Oceanic Engineering, vol. 27, no2, April 2002

[7]. Bob Seymour MTTF, Failrate, Reliability And Life Testing Application Bulletin Burr-Brown AB-059. 1993.

[8]. Ham Jeff. Application Engineer, Vicor. The basics of heat Management for DC/DC converters. ECN October 2005

[9]. Roger Paul Stout, PE Predicting Thermal Runaway application note AND8223/ ON Semiconductor. April, 2006

[10].Gary e. Dashney. Basic semiconductor thermal measurement. Motorola Application Note AN 1570/D. 1995

[11]. Xingcun Colin Tong. Advanced Materials for Thermal Management of Electronic Packaging. Springer New York 2011 ISBN978-1-4419-7758-8

[12].Lall, B.S.; Ortega, A.; Kabir, H.; Thermal design rules for electronic components on conducting boards in passively cooled enclosures. Thermal Phenomena in Electronic Systems, 1994. I-THERM IV. InterSociet. 4-7 May 1994. ISBN: 0-7803-1372-0

[13].Ying Feng Pang. Assessment of Thermal Behavior and Development of Thermal Design Guidelines for Integrated Power Electronics Modules Dissertation submitted to the faculty of the Virginia Polytechnic Institute and State. 2005 
[14].Jane W. Maclachlan Spicer; Dale W. Wilson; Robert Osiander; J. Thomas; Ben O. Oni Evaluation of highthermal-conductivity graphite fibers for thermal management in electronics applications Thermosense XXI19 March 1999

[15].Krenkel,. R. NaslainH. Schneider Ceramic Foams and Their Applications. Published Online: 13 JAN 2006 DOI: 10.1002/3527605622.ch124. Copyright (C) 2001 WileyVCH Verlag GmbH

[16].Hyejin Moon, Shreyas Bindiganavale, Yasith Nanayakkara and Daniel W. Armstrong, Digital Microfluidic Device Using Ionic Liquids for Electronic Hotspot Cooling. In SME 2009 7th International Conference on Nanochannels, Microchannels and Minichannels, pp. 131-135, Pohang, South Korea, June 22-24, 2009, doi:10.1115/ICNMM2009-82264

[17].Jung-Chang Wang. L-type heat pipes application in electronic cooling system. In.Inter Journal Thermal Sciences 50 (2011) pp97-105. Elsevier

[18].ANSI/VITA 51.1, American National Standard for Reliability Prediction, MIL-HDBK-217 Subsidiary Specification, VMEbus International Trade Association, 2008.

[19]. S. Yang, D. Xiang, A. Bryant, P. Mawby, L. Ran and P. Tavner, "Condition monitoring for device reliability in power electronic converters: a review." IEEE Trans. on Power Electron., vol. 25, no. 11 , pp. 2734-2752, Nov., 2010.

[20].Huai Wang; Ke Ma; Blaabjerg, F., "Design for reliability of power electronic systems," IECON 2012 - 38th Annual Conference on IEEE Industrial Electronics Society , vol., no., pp.33,44, 25-28 Oct. 2012

[21]. Sheppard, D.C. Seas at the millennium: an environmental evaluation Vol. 3. Global issues and processes. 2000, Pergamon Press, Amsterdam and Oxford.

[22].Godø, O.R. What can technology offer the future fisheries scientist - possibilities for obtaining better estimates of stock abundance by direct observations. In J. North w. Atl. Fish. Sci. 1998, 23, 105-131.

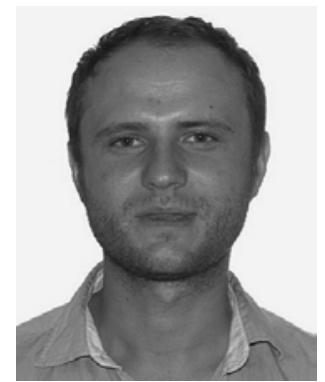

Daniel Mihai Toma received the M.Sc. degree in electrical engineering from the Technical University "Gheorghe Asachi," Iasi, Romania, in 2008 and the Ph.D. degree in electronic engineering from the Universitat Politècnica de Catalunya (UPC), Barcelona, Spain, in 2012.

$\mathrm{He}$ is currently a member of the research group "Remote Acquisition Systems and Data Processing (SARTI)," UPC. His current research interests include electronic instrumentation, marine sensor networks, wireless ad hoc networks, interoperability in sensor networks, and synchronization and scheduling. Dr. Daniel Mihai Toma is a member of the IEEE Oceanic Engineering Society, the Open Geospatial Consortium (OGC), the Smart Ocean
Sensors Consortium and PUCK Standard Working Group (SWG) and the European Seafloor Observatories Network (ESONET).

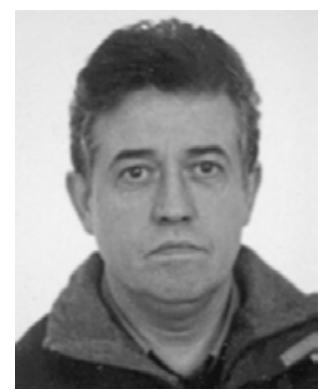

Antoni Mànuel-Làzaro was born in Barcelona, Spain, in 1954. He received a degree in telecommunication engineering from the Universitat Politècnica de Catalunya (UPC), Barcelona, Spain, in 1980 and the $\mathrm{Ph} . \mathrm{D}$. degree in telecommunication engineering from UPC in 1996.

Since 1988, he has been an Associate Professor in the Department of Electronic Engineering, UPC, where he is the Director of the research group "Remote Acquisition Systems and Data Processing (SARTI)," which comprises 21 researchers. SARTI is member of the Technological Innovation Centre network within the Catalonia government (March 2001). He is the coordinator of the Tecnoterra associated unit of the Scientific Research Council through the Jaume Almera Earth Sciences Institute and the Marine Science Institute. His current research interests are in applications of automatic measurement systems based on the concept of virtual instrumentation and oceanic environment. $\mathrm{He}$ is the author and coauthor of numerous papers in international journals, four patents, eight books on instrumentation and numerous communications in international congresses, in the area of electronic instrumentation.

Currently, he is involved in more than ten projects with the industry and several funded public research projects. Prof. Mànuel-Làzaro is a member of the IEEE Oceanic Engineering Society, the IEEE Signal Processing Society, the IEEE Instrumentation and Measurement Society, the IEEE Education Society, the IEEE Power Electronics Society, the IEEE Computer Society, the IEEE Communications Society, the Open Geospatial Consortium (OGC), and the European Seafloor Observatories Network (ESONET).

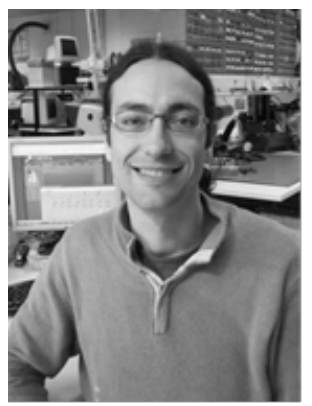

Marc Nogueras was born in Catalonia, Spain, in 1976. He received his $\mathrm{Bs}$ and Ms degrees in Telecommunication Engineering, in 1999 and 2003 respectively from Universitat Politècnica de Catalunya (UPC), Spain and a Master's Degree in Electronic Engineering in 2012 from Universitat Rovira i Virgili (URV). He worked four years in GNE (Global Networking Engineering) developing projects and installing optical communications systems for electrical utilities and since 2006 is working as an applications engineer in the research group "Remote acquisition systems and data processing (SARTI)" coordinating and developing the project for the construction of the OBSEA a wired underwater observatory. Since 2006, has made more than 15 contributions to international conferences on marine technology and several articles in scientific journals. 


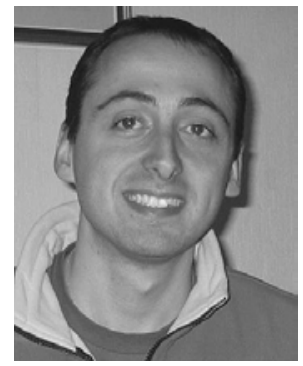

Joaquín Del Río was born in Catalonia, Spain, in 1976. He received the B.S., M.S., and Ph.D. degrees in telecommunication engineering and electronic engineering from the Universitat Politècnica de Catalunya (UPC), Barcelona, Spain, in 1999, 2002, and 2011, respectively.

Since 2001, he has been a Professor at the Electronic Engineering Department, UPC. He is a member of the research group "Remote Acquisition Systems and Data Processing (SARTI)." His research is focused on electronic instrumentation, interoperability in marine sensor networks, and wireless sensor networks. He is a member of the NIST IEEE1451.2 Working Group and the Smart Ocean Sensors Consortium and PUCK Standard Working Group (SWG). He is involved in projects within the industry and funded public research projects and is a National Instruments Certified Instructor for teaching official LabVIEW courses. 